\title{
Hitting Them With Carrots: Voter Intimidation and Vote Buying in Russia - CORRIGENDUM
}

Timothy Frye, Ora John Reuter and David Szakonyi

doi:10.1017/S0007123416000752, Published by Cambridge University Press, 5 February 2018.

The authors apologise for errors in the Acknowledgements in the original article. They should read:

Political Science Department, Columbia University (email: tmf2@columbia.edu); Political Science Department, University of Wisconsin-Milwaukee (email: reutero@uwm.edu); Political Science Department, George Washington University (email: dszakonyi@gwu.edu). All three authors are affiliated with the National Research University, Higher School of Economics located in Moscow, Russia.

The study has been funded within the framework of the Basic Research Program at the National Research University Higher School of Economics (HSE) and by the Russian Academic Excellence Project '5-100.

Data replication sets are available in Harvard Dataverse at: https://dx.doi.org/10.7910/DVN/WMRQ16 and online appendices are available at https://doi.org/10.1017/S0007123416000752.

\section{Reference}

Frye T, Reuter OJ and Szakonyi D. Hitting Them With Carrots: Voter Intimidation and Vote Buying in Russia. British Journal of Political Science. Published by Cambridge University Press, 5 February 2018. doi:10.1017/S0007123416000752. 